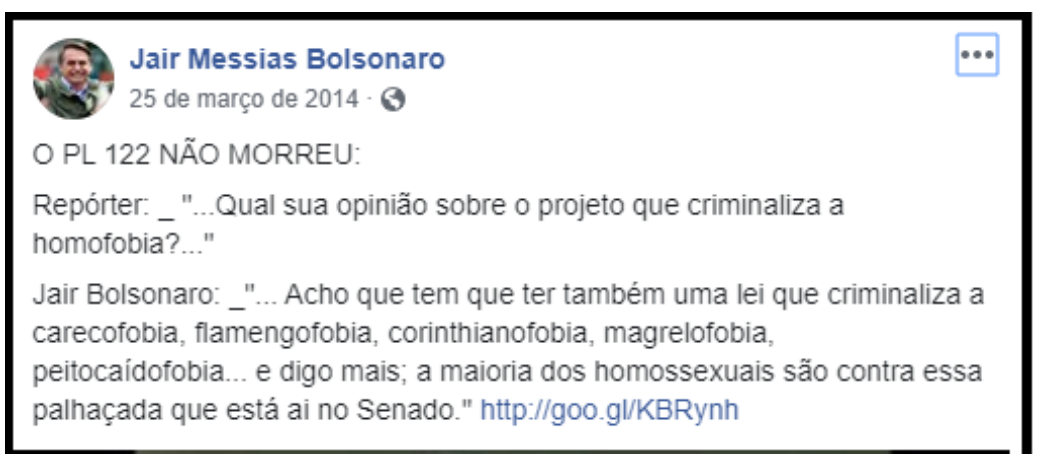

\title{
Uma análise argumentativa do sentido de "homofobia" na enunciação de Jair Bolsonaro (2014) ${ }^{1}$
}

An argumentative analysis of the sense of "homophobia" in Bolsonaro's enunciation

\author{
Wellton da Silva de Fatima ${ }^{2}$ \\ ORCID: https://orcid.org/0000-0002-0526-5396
}

Resumo: Circunscritos à chamada semântica argumentativa, estabelecida a partir dos estudos de O. Ducrot $(1972 ; 1976)$, analisamos uma postagem no Facebook em que o deputado Jair Bolsonaro, em sua enunciação, mobiliza a palavra "homofobia". Partindo dessa postagem - e considerando sua especificidade material -, investigamos a existência de elementos enunciativos como a ironia, a negação e os operadores argumentativos, partindo da teoria da argumentação na língua (Ducrot \& Anscombre, 1976), para demonstrar o modo como se sustentara o sentido de "homofobia". Suspeitando da necessidade de considerar a existência de uma exterioridade constitutiva produzindo efeito na enunciação de Bolsonaro, trouxemos à discussão os gestos teóricos de Guimarães (1995) e Orlandi $(1987,1998)$ para refletir sobre o funcionamento do político, tal como teorizado na semântica do acontecimento e na análise do discurso. Em nossos resultados, demos relevo à importância de considerar a relação entre língua e exterioridade para a compreensão dos processos semânticos.

Palavras-chave: Enunciação; Argumentação; Político; Bolsonaro; Homofobia.

Abstract: We circumscribed to the so-called argumentative semantics, established from the studies of O. Ducrot $(1972 ; 1976)$, to we analyzed a Facebook post in which deputy Jair Bolsonaro, in his statement, mobilizes the word "homophobia". Starting from this post - and considering its material specificity -, we investigated the existence of enunciative elements such as irony, negation and argumentative operators, starting from the theory of argumentation in language (Ducrot \& Anscombre, 1976), to demonstrate the homophobia's sense in the Bolsonaro's discourse. Suspecting the need to consider the existence of a constitutive exteriority having an effect on Bolsonaro's enunciation, we brought to the discussion the theoretical gestures of Guimarães (1995) and Orlandi $(1987,1998)$ to reflect on the functioning of the political, as theorized in "event semantics" and discourse analysis. In our results, we emphasized the importance of considering the relationship between language and exteriority for the understanding of semantic processes.

Keywords: Enunciation; Argumentation; Political; Bolsonaro; Homophobia.

\footnotetext{
${ }^{1}$ Agradeço à professora Sheila Elias do Nascimento, do IEL/Unicamp, pelas orientações no exame de qualificação, o que possibilitou a construção deste artigo.

${ }^{2}$ Professor no Instituto Federal de Alagoas e doutorando pelo Programa de Pós-Graduação em Linguística da Unicamp na área de Análise do Discurso. E-mail: wellton.fatima@ifal.edu.br.
} 


\section{Introdução}

Em março de 2014, no Brasil, foi possível testemunhar acalorado debate público e institucional acerca de um projeto de lei que tramitara na Câmara dos Deputados em Brasília/DF. O PL 122 propunha a criminalização da latente homofobia existente no cenário nacional brasileiro e era alvo de intensa disputa política, que evidenciou a divisão da opinião pública de modo geral.

O projeto vinha sendo defendido por congressistas que se alinhavam à esquerda política brasileira; já a condenação da pauta partia de congressistas alinhados à, assim por eles chamada, direita conservadora. Não demorou muito até que esse debate chegasse às redes sociais de internet. Havia, nesse momento, as vindouras eleições presidenciais, que acirraram o debate público e que, talvez pela primeira vez, tiveram nas redes sociais de internet um fértil e decisivo lugar de realização.

É dessa movimentação e desses embates que recortamos o fato de linguagem que nos instigou teoricamente. Nesse mesmo mês, o então deputado e pré-candidato à presidência da república Jair Bolsonaro fez uma postagem em sua página na rede social Facebook sobre o assunto. É principalmente o sentido do enunciado "Acho que tem que ter também uma lei que criminaliza a carecofobia, flamengofobia, corithianofobia, magrelofobia, peitocaídofobia ... e digo mais; a maioria dos homossexuais é contra essa palhaçada que está ai no Senado”, em resposta ao enunciado “...Qual sua opinião sobre o projeto que criminaliza a homofobia??..." - em sua formulação e constituição - que nos interessa.

Neste trabalho, adotaremos uma perspectiva semântica específica em busca de dar conta de problemas também específicos em que se colocam as questões da significação e do sentido. A saber: o modo como a argumentação se torna possível na ordem da língua, sendo mobilizada pelo funcionamento do político na enunciação nos domínios da política partidária em redes sociais de internet ${ }^{3}$.

Tendo em vista observar essa relação - entre o político e a política partidária -, a enunciação - enquanto o acontecimento constituído pelo aparecimento de um enunciado (DUCROT, 1987, p. 168) - é, portanto, um elemento fundamental para nosso olhar analítico, já que a tomada da palavra é o modo pelo qual se materializa o dizer. E é este último que possibilita compreendermos posições, divisões e tensões que constituem o processo de significação.

\footnotetext{
3 Para efeitos didáticos, distinguiremos as noções de político e de política na próxima seção, circunscrevendo o primeiro em um quadro teórico específico.
} 
Temos no horizonte traçar um percurso pelo tratamento teórico dado a algumas noções caras à Semântica Argumentativa para, depois, compreender o modo como a consideração do político, a partir de um ponto de vista materialista, pode contribuir para a análise do corpus que selecionamos.

Desse modo, primeiramente partimos dos postulados de Ducrot \& Anscombre (1976), em sua Teoria da Argumentação na Língua, para produzir uma análise sobre os modos pelos quais se apresenta a argumentação em uma perspectiva semântica estrutural. Consideramos, ainda nessa perspectiva de princípio estruturalista, a teoria polifônica da enunciação (DUCROT, 1987 [1984]) e a maneira como nela mobiliza-se o estatuto da argumentação em enunciados por meio dos quais se mostram presentes responsabilidades e pontos de vista por aquilo que é dito. Assim, colocamos em questão a suposta unicidade do sujeito falante (DUCROT, 1987, p. 161).

Em busca de um tratamento teórico adequado para responder às nossas questões frente à articulação argumentativa presente em tais enunciados, revisitamos as discussões de Ducrot (1988) sobre o funcionamento da argumentação em face aos topoi para compreender a necessidade de (re)considerar a relação entre língua e exterioridade na produção dos sentidos. Deparando-nos com os limites da teorização proposta, nesse momento, pelo autor, fizemos intervir, a partir da tomada de posição materialista, o gesto teórico de Guimarães (1995), para compreender a maneira como o político - tal como teorizado nos domínios da Análise de Discurso materialista (PÊCHEUX, 1969) (ORLANDI, 1987) - se inscreve na ordem da língua, possibilitando certos encadeamentos argumentativos o que, por sua vez, determina a produção do sentido dos enunciados. Partindo da ideia de que a existência da argumentação atesta o fato de que há uma divisão posta na produção de sentidos, mobilizamos noções como a de interdiscurso para demonstrar que a argumentação e seu modo de se apresentar na ordem da língua é já determinada pela historicidade e pelo funcionamento da ideologia.

Desse modo, organizamos na próxima seção a apresentação dos pressupostos teóricos que nortearão a nossa análise, indicando a abordagem à qual seguiremos; em seguida, procedemos a uma série de análises sobre os enunciados que recortamos, a fim de demonstrar a maneira como esses enunciados se articulam argumentativamente em perspectiva estrutural, tendo em vista as figuras da enunciação e as camadas do enunciado; finalmente, fazemos algumas considerações a partir da noção de político, centrando a discussão sobre os fatos de linguagem em tela a partir da tomada de posição materialista. 


\section{Fundamentação teórica}

Na década de 1970, na França, Oswald Ducrot propõe sua Teoria da Argumentação na Língua (ANL) ${ }^{4}$, possibilitando-nos, hoje, compreender o sentido dos enunciados a partir de encadeamentos possíveis na língua. Esse gesto teórico fundador nos permite compreender processos no interior dos quais constituem-se como fundamentais as figuras da enunciação e as camadas do enunciado.

Para Ducrot \& Anscombre (1976), o sentido de enunciados e das palavras que o compõem não se constituem de outro modo se não pelas conclusões que deles podem ser tiradas. Assim, para os autores, é pela relação entre argumentos e conclusões que se constitui um sentido. Trata-se de uma abordagem semântica estruturalista, isto é, que pensa a produção dos sentidos a partir da relação de elementos que estão estruturalmente dispostos. O estruturalismo em Ducrot tem como objeto a linguagem, portanto considera a língua - e sua estrutura - tendo em vista o funcionamento da enunciação.

É necessário salientar que, para os autores, a argumentação se dá em uma perspectiva estrutural. Desse modo, a noção de argumentação adotada difere-se daquela das abordagens que pensam o convencimento, a persuasão, etc. Esta última seria a argumentação retórica, enquanto a que interessa para o autor, e também para nós, é a argumentação linguística (Ducrot, 2009).

O ponto que mais interessa, para a discussão que aqui pretendemos, é o fato de que, para Ducrot (1987, p. 161), a partir da ANL, a unicidade do sujeito falante, pressuposta então pela chamada linguística moderna, não existe. Por meio de seu esboço de uma teoria polifônica da enunciação, o autor passa, pois, a demonstrar como funcionam as camadas do enunciado e as figuras da enunciação em seu encadeamento argumentativo.

Note-se que, na perspectiva de Oswald Ducrot, portanto, é necessário romper com certa tradição que se instaurou na Semântica, que buscava observar o sentido da palavra fora das relações que a constituem. Para o autor, o sentido da palavra é aquele produzido no interior de um enunciado. Os enunciados, por sua vez, têm seus sentidos produzidos a partir da enunciação. Segundo Ducrot, devemos considerar "a descrição semântica de uma língua como uma máquina suscetível de fazer corresponder a cada enunciação (isto é, a cada emprego de um enunciado em uma situação) o sentido que os sujeitos falantes, de fato, atribuem-lhe" (DUCROT, 1987, p. 56). É nessa perspectiva que recusamos

\footnotetext{
${ }^{4}$ A sigla ANL (Argumentação Na Língua) é a tradução veiculada por estudiosos brasileiros da ADL (Argumentation Dans la Langue), tal como dada a conhecer e circular por Oswald Ducrot.
} 
qualquer vertente teórica que compreenda serem fixos e imutáveis os sentidos das palavras e enunciados.

Valendo-nos dos pressupostos que temos descrito até aqui, buscamos produzir uma análise semântica, de cunho estrutural, para compreender, em nosso corpus, os sentidos que se apresentam a partir dos enunciados em questão.

Suspeitamos, no entanto, que seria necessário considerar algo que fosse exterior à língua - e ao mesmo tempo lhe constituísse - para compreender determinadas especificidades de nosso objeto, sem, contudo, abrir mãos de algumas valiosas discussões produzidas pela perspectiva estrutural. Essa suspeita tem, de algum modo, a ver com os motivos que levam Oswald Ducrot, na segunda fase de sua ADL, a propor os topoi argumentativos. Por isso, não acompanhamos o autor na terceira fase de suas elaborações teóricas, em sua Teoria dos Blocos Semânticos. De outro modo, buscamos relações teóricas de vizinhança que possibilitam a compreensão de como uma certa exterioridade é já em relação à língua e lhe constitui.

É justamente neste ponto que buscamos uma filiação ao materialismo histórico e adotamos a compreensão do político na linguagem como fundamento, tendo em vista o fato de que assumir esse pressuposto produz efeitos em nosso olhar analítico. Com Guimarães (1995), em seus gestos teóricos, notadamente a consideração do político na linguagem, a partir das elaborações de Oswald Ducrot, foi possível compreender a necessidade dessa filiação e o modo como ela se dá.

Para tanto, valemo-nos dos gestos teóricos e analíticos de Guimarães (1995; 2017), mais especificamente a retomada da noção de político a partir de Rancière (1994). Para além disso, baseamo-nos nas elaborações de Elias de Oliveira $(1998,2014)$ e ZoppiFontana (2014), tendo em vista a aproximação feita por essas autoras com a noção de político advinda da teoria da Análise de Discurso, principalmente aquela desenvolvida no Brasil por Orlandi (2013), a partir dos gestos teóricos de Pêcheux (1969; 1975). Tais gestos e elaborações teóricas e analíticas nos permitem objetar sobre uma exterioridade que sobredetermina as práticas linguageiras.

Para Orlandi (1998, p. 74) há de se observar dois fatos ao adotarmos como constitutiva a relação entre língua e exterioridade, tendo em vista a questão da argumentação: "1. a noção de antecipação, sustentada pelo funcionamento das formações imaginárias (posições-sujeito); 2. a noção de esquecimento ligada ao interdiscurso (exterioridade discursiva)". Assim, a argumentação é um fato de linguagem que se dá na ordem da formulação a partir das imagens produzidas entre os interlocutores inscritos em 
posições-sujeito no discurso. Essas imagens são produzidas por um sujeito interpelado ideologicamente e constituído pela ilusão de que suas palavras são suas, de fato, e não uma rede de memórias que o atravessa, intervindo em cada gesto de tomada de palavra.

A autora propõe o trabalho com a textualização do político, segundo a qual o aparecimento de um enunciado pode ser compreendido como a materialização de conflitos na ordem da língua, constituído a partir de memórias. Para Orlandi (1998, p. 75), “não há sentido que não tenha sido produzido em condições específicas, em uma relação com a exterioridade, com uma direção histórico-social que se produz em relações imaginárias que derivam de um trabalho simbólico".

Neste ponto, tornam-se necessários dois esclarecimentos importantes:

1) Para efeito didático, diferenciaremos a noção teórica de político da noção de política tal como pensada no senso comum. Embora, em termos teóricos, uma noção recubra a outra, foi necessário estabelecer essa divisão para que se saiba quando estamos nos referindo à noção teórica e quando estamos nos referindo à prática política ordinária. Tomaremos esta última como a política partidária, isto é, como aquele domínio da administração, gerência e governança daquilo que é ou deveria ser - comum a todos. Trata-se, portanto, de uma prática institucionalizada de busca pela legitimação de posições;

2) A noção de político é diferente na Análise do Discurso e na Semântica do Acontecimento (2017 [2002]) - esta última enquanto um campo fundado por Eduardo Guimarães, em suas reflexões sobre a enunciação. Para Guimarães, o político (ou a política) é "caracterizado pela contradição de uma normatividade que estabelece (desigualmente) uma divisão do real e a afirmação de pertencimento dos que não estão incluídos" (2017, p. 22). Já para Orlandi (1996, p. 21-22), a noção de político diz respeito ao fato de que "o sentido é sempre dividido, tendo uma direção que se especifica na história, pelo mecanismo ideológico de sua constituição". De acordo com Elias de Oliveira (2014, p. 41), “o político na Análise do Discurso diz respeito às divisões interdiscursivas, isto é, àquelas que concernem às relações entre o dizer e sua constituição ideológica, pela inscrição na memória discursiva". Ainda segundo a autora (Ibidem), diferentemente, "na semântica do Acontecimento, o político diz respeito às divisões enunciativas na configuração do dizer, isto é, àquelas concernentes às representações dos sujeitos e aos gestos de afirmação de pertencimento desses sujeitos em relação ao objeto do dizer". Tendo em vista, em primeiro lugar, o 
aprofundamento e as bases teóricas específicas de cada um desses campos, e, em segundo lugar, os objetivos e limitações da análise que aqui propomos, trabalharemos na relação entre essas duas noções de político articuladas, levando em consideração, ainda segundo Elias de Oliveira (1998), que "os conceitos de político desses dois domínios teóricos ligados pela filiação ao materialismo histórico podem dar a ambas as abordagens, a enunciativa e a discursiva, maior capacidade heurística" (p. 52).

Desse modo, damos sequência ao nosso gesto analítico, tendo em vista a determinação histórica dos processos semânticos, dentre eles a argumentação.

A seguir, trazemos nossas análises do fato de linguagem que constitui nosso corpus, em busca de dar visibilidade ao encadeamento argumentativo nos termos de uma semântica estrutural. Em seguida, convocamos a noção de político novamente, trazendo, em momento oportuno, conceitos e noções que dão contorno a ela, tendo sempre em vista a filiação ao materialismo histórico.

Procedemos, pois, à análise de enunciados recortados ${ }^{5}$ das redes sociais do então deputado e pré-candidato à presidência da república Jair Bolsonaro. Nosso objetivo, ao analisar tais enunciados, materializados em uma postagem no perfil oficial do Facebook de Bolsonaro, é compreender como é mobilizada a palavra "homofobia". Para tanto, centramo-nos na análise do funcionamento de elementos de ordem enunciativa, tais como a ironia, a negação e os operadores argumentativos.

\section{Nossas análises}

Como afirmamos, nosso objeto de análise são enunciados formulados na rede social de internet Facebook por Jair Messias Bolsonaro. Na figura abaixo, é possível observar um print screen que captura o fato de linguagem que elencamos como corpus de análise para as reflexões ora propostas.

5 Trabalhamos com a noção de recorte (Orlandi, 1984), em busca de depreender o funcionamento argumentativo em fragmentos de linguagem-e-situação. A autora parte da ideia de que "é fugidio o limite entre o dizer e o não dizer" (p. 9) para negar uma abordagem que tome a análise dos fatos de linguagem em sua unidade e segmentação para partir de uma abordagem que compreenda a existência de unidades discursivas por meio das quais é possível compreender processos de produção de sentido tendo em vista a relação tensa entre paráfrase e polissemia. 


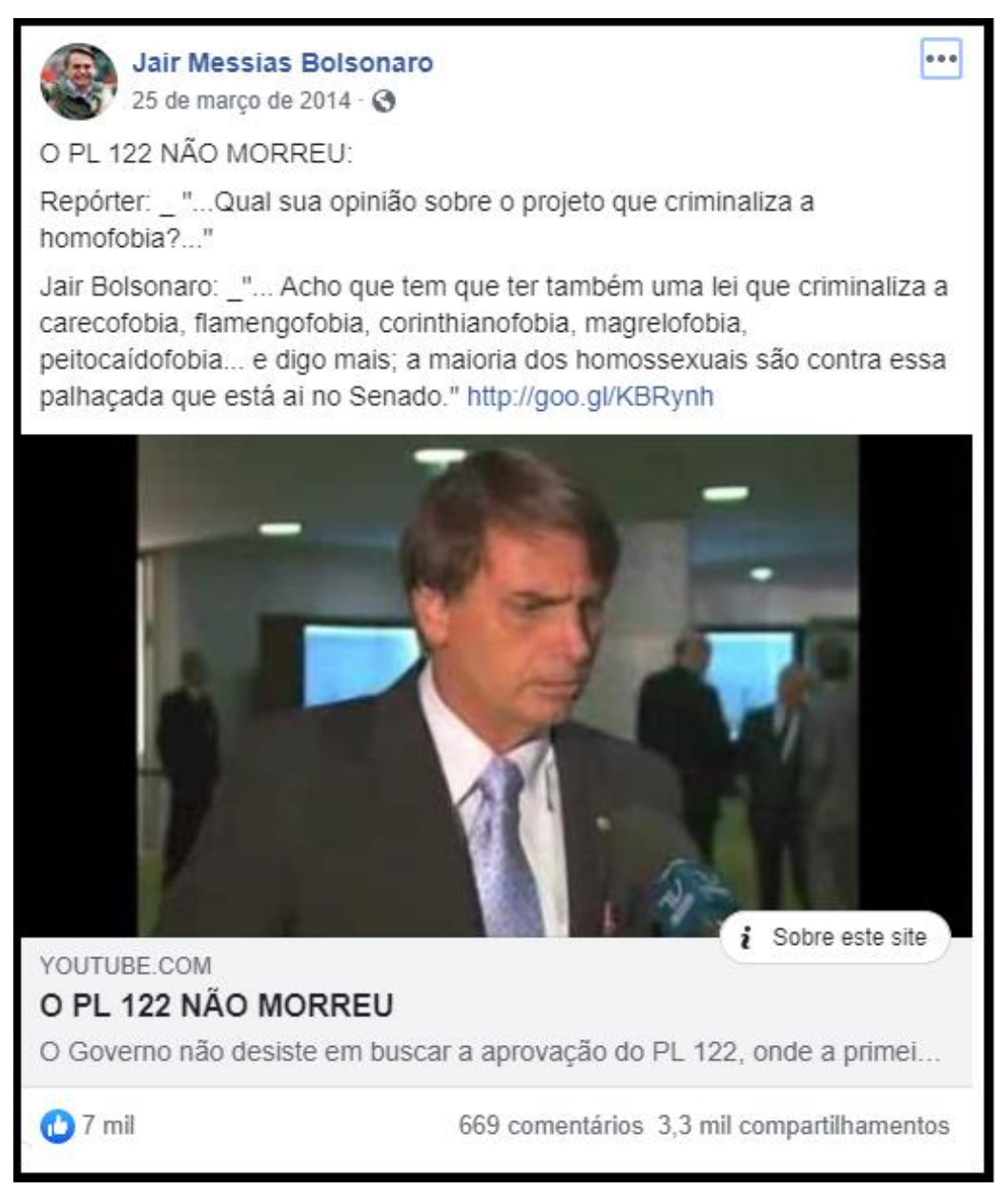

Figura 1: print screen da postagem feita por Jair Bolsonaro em sua página oficial no Facebook Fonte: o autor.

Dito isso, sejam, então, os enunciados que analisamos:

O PL 122 NÃO MORREU:

Repórter: _ “...Qual sua opinião sobre o projeto que criminaliza a homofobia??..."

Jair Bolsonaro: _ “... Acho que tem que ter também uma lei que criminaliza a carecofobia, flamengofobia, corithianofobia, magrelofobia, peitocaídofobia... e digo mais; a maioria dos homossexuais é contra essa palhaçada que está aí no Senado."

Os enunciados supratranscritos foram publicados no dia 25 de março de 2014 na página oficial no Facebook de Jair Messias Bolsonaro, atualmente Presidente da República do Brasil. Na ocasião, Bolsonaro era deputado federal, pelo Rio de Janeiro, em seu $6^{\circ}$ mandato. A postagem conta, hoje, com mais de 7 mil reações e um grande volume de comentários e compartilhamentos.

O que vemos, ao acessar a postagem, é um print que recorta um frame, isto é, uma captura de tela, de um vídeo de uma entrevista dada por Jair Bolsonaro a uma repórter no 
salão nobre na saída de uma sessão da Câmara dos Deputados em Brasília/DF. Na imagem, vemos a figura de Bolsonaro, da região do busto para cima; o salão nobre da Câmara ao fundo; e a mão da repórter segurando o microfone. Acima da imagem, temos os enunciados que analisamos - e que estão transcritos no início desta seção - e o link para o vídeo da entrevista por ele concedida. O vídeo em si tem mais de quatro minutos de duração. Nele, Bolsonaro aborda o projeto de criminalização da homofobia a partir da sua ótica. Observe-se que, portanto, é o ponto de vista expresso por Bolsonaro que está em questão. Tendo em vista que Bolsonaro toma a palavra durante toda a extensão de quatro minutos do vídeo e que não há interrupção ou silêncio em nenhum momento, é possível constatar, facilmente, que há muito mais texto no vídeo do que o que vemos transcrito na rede social. Os enunciados que acompanham o link - e que recortamos para analisar - não são, desse modo, transcrição exata em relação ao vídeo. É uma reescritura mais ou menos fiel que, como poderia se esperar, ignora hesitações, erros de pronúncia, falhas da voz, etc. Note-se, de outro modo, que a reescritura também edita o "conteúdo" do vídeo, linearizando o dizer da entrevista - longa demais para ser transformada em texto de rede social e, potencialmente, viralizar.

Nosso objeto de análise - os enunciados supratranscritos - é, já na superfície, bem heterogêneo. Além da parte, entre aspas, que se configura como reescritura da fala de Bolsonaro, há, também, um dizer em caixa alta - que não consta no vídeo, mas está ali enunciado na rede social - e, também, uma fala, entre aspas, atribuída à repórter.

O digital, com sua ordem própria, possui algumas especificidades de origem enunciativa. Gostaríamos de salientar algumas, pela forma como comparecem nos enunciados que analisamos.

Em primeiro lugar, a atribuição de responsabilidade pelo enunciado - o que toca diretamente no estatuto dado à noção de locutor - é já demarcada, ainda que imaginariamente, pelo próprio nome do perfil e pela foto que a acompanha. Queremos dizer que, de certo modo, as postagens já vêm potencialmente assinadas por um locutor - desde que não haja marcas enunciativas que atribuam o enunciado a outra pessoa -, que se responsabiliza pela página e, consequentemente, por tudo que se posta nela ${ }^{6}$. Isso porque, de acordo com Ducrot, o locutor é "um ser que é, no próprio sentido do

6 Essa é uma questão importante que explica o porquê tomarmos Jair Bolsonaro como locutor, ainda que saibamos que, muito provavelmente, há uma equipe que também atualiza suas redes sociais de internet ainda mais atualmente, dado o fato de que Bolsonaro ocupa a Presidência da República. 
enunciado, apresentado como seu responsável, ou seja, como alguém a quem se deve imputar a responsabilidade deste enunciado" (1987, p. 182).

Outro elemento que gostaríamos de destacar é o funcionamento enunciativo da caixa alta. Por convenção de uso da língua no espaço virtual, escrever em caixa alta corresponde a gritar. Do ponto de vista enunciativo, gritar, por sua vez, é dizer de um certo modo, colocando no enunciado marcas retóricas específicas que direcionaram os argumentos ali contidos para uma determinada conclusão. Assim, o enunciado "O PL 122 NÃO MORREU" comparece como grito, encaminhando uma determinada força ilocucional, ou seja, pela existência dessa marca - a caixa alta - modifica-se a situação jurídica entre os interlocutores. É como se, ao utilizar a caixa alta, o locutor assinalasse de modo alarmado o engano de se acreditar que o PL 122 morreu. Não se trata, desse modo, de uma simples afirmação - contendo em seu interior uma negação -, mas de uma espécie de aviso, de alerta.

Há, ainda, a especificidade da reescritura do enunciado. Como dissemos, os enunciados que analisamos são transcrições mais ou menos fiéis do que se diz no vídeo. Ocorre, no entanto, que no gesto de transcrição da fala pela página há a inserção das reticências. Se, por um lado, na oralidade de um modo geral, como no vídeo por exemplo, não existe um marcador para a reticência - ou seja, na fala, elas são percebidas pela ausência, pelo silêncio e não pelo preenchimento de um som -, na escrita elas se formulam, agora sob a responsabilidade desse locutor ${ }^{7}$ da rede social, e se marcam nesse novo enunciado. Isso tem implicações de ordem enunciativa. Ao inserir as reticências, o enunciado não finaliza a cadeia enumerativa que estava se montando, deixando o seu final em suspenso. Compreendemos que a presença das reticências argumenta em favor do não ponto final das fobias ${ }^{8}$ e, desse modo, argumenta em direção a um sem número de “fobias" paralelas à homofobia e que, portanto, situam-na como apenas mais uma coisa entre $n$ outras coisas.

Além da inserção das reticências, a reescritura traz a inserção das aspas, elemento também estranho à oralidade e familiar à escrita, tal como as reticências. Apesar de ser comum tomarmos, do ponto de vista enunciativo, as aspas como uma marca de distanciamento, nesse caso as aspas nas quais se inserem a pergunta da repórter e a

\footnotetext{
${ }^{7}$ Observe-se que damos um novo estatuto para o locutor, diferente daquele do vídeo. Trata-se de um novo modo de atribuição de responsabilidade pelo enunciado, próprio do virtual, das redes sociais de internet. Mais à frente trataremos disso.

${ }^{8}$ Conforme veremos mais à frente.
} 
resposta de Bolsonaro direcionam o leitor para o fato mesmo da reescritura. Dito de outro modo, as aspas apontam os enunciados ali transcritos como "reproduções" daquilo que se disse no vídeo, cujo print está logo abaixo dos dizeres em linguagem verbal e cujo link de acesso está em anexo aos enunciados.

Visando a um primeiro gesto de dessuperficialização de nosso objeto para tratálo do ponto de vista teórico e, além disso, em busca de melhor organizar nossa análise, dividimo-la em tópicos, de acordo com as categorias trabalhadas por Ducrot em sua teoria da polifonia e sobre alguns aspectos lexicológicos para, em seguida, fazer considerações mais específicas no que se refere à tomada de posição materialista.

Desse modo, passemos a análise das categorias uma a uma.

\subsection{A negação}

Nos termos de Ducrot, no enunciado "O PL 122 NÃO MORREU" temos uma negação descritiva ${ }^{9}$. Ou, pelo menos, é assim que a tomaremos nesse primeiro gesto de incursão analítica tendo em vista os objetivos supramencionados deste trabalho.

Vale ressaltar que, em um primeiro momento da teoria (Ducrot, 1972), encontramos apenas duas formas de negação: a polêmica e a descritiva. No entanto, acompanharemos o gesto teórico do autor ao propor sua teoria polifônica da enunciação, compreendendo a existência de três formas de negação: a descritiva, a polêmica e a metalinguística.

O autor, a partir da teoria polifônica, considera a negação descritiva como "um derivado delocutivo da negação polêmica" (DUCROT, 1987, p. 204), mas ainda tendo em vista que a negação descritiva "serve para representar um estado de coisas sem que o autor apresente sua fala como se opondo a um discurso contrário" (DUCROT, 1987, p. 203).

Diferentemente da negação polêmica, que nega a enunciação, a negação descritiva se coloca a negar o predicado do enunciado, nega-se o ponto de vista, portanto. O locutor, nesse caso, associa-se à posição do $\mathrm{E}^{2}$ (enunciador 2), o que sustenta a negação, opondose ao $\mathrm{E}^{1}$, que sustenta o ponto de vista de que "o PL 122 morreu".

\footnotetext{
9 Adiante, quando mobilizarmos o conceito de interdiscurso, sustentaremos outra possibilidade de compreender essa negação na relação com a memória. Trabalharemos, sobretudo, na direção de compreender até que ponto podemos afirmar que esta enunciação não nega uma afirmação anterior, considerando-se que as condições de produção deste enunciado possam apontar para uma oposição a outros dizeres.
} 
É importante considerar, nesse caso, que o pressuposto do enunciado se mantém. O enunciado “o PL 122 não morreu” sustenta o pressuposto de que o PL continua vivo.

Temos, desse modo:

$p \rightarrow \mathrm{O}$ PL não morreu

$q \rightarrow \mathrm{O}$ PL continua vivo

Sendo

$$
p \rightarrow q
$$

O PL 122 não morreu $\rightarrow$ ele continua vivo

O que acabamos de afirmar tem a ver com propriedade lexical do verbo "morrer", que produz um efeito que merece atenção. Note-se que "morrer", em sua significação, anula a possibilidade de "viver". Não há gradação como "um pouco vivo", ou "bastante vivo" nesse sentido. Quando não se pode atestar o fato "viver" é porque o fato "morrer" já se atestou. Logo, se "não morreu" não é porque simplesmente "vive", isto é: o dizer de "não morrer" convoca como pressuposto um "ainda vive", ou, como dissemos um "continua vivo/vivendo".

Ainda tratando desse enunciado em que se insere a negação, é necessário destacar a existência de, em termos ducrotianos, um subentendido. Considerando-se a relação entre "morrer" e "viver" explanada acima e a configuração da negação no interior do enunciado "O PL 122 não morreu” é possível constatar que a argumentação vai na direção da conclusão de que "O PL continua vivo", enquanto pressuposto, "embora não devesse", enquanto subentendido.

Desse modo, temos

$$
p \rightarrow q-s
$$

O PL não morreu $\rightarrow$ ele continua vivo - embora não devesse ${ }^{10}$

Sendo $s$ o subentendido.

A articulação que aqui se apresenta dialoga com o que Ducrot (1987, p. 185) discute a respeito da necessidade de desdobramento do enunciado, conforme pressupõe o conceito de polifonia. "Essa possibilidade de desdobramento [da atribuição de

10 Mais à frente, quando fizermos intervir a posição materialista em nossa análise, retomaremos a existência desse subentendido no corpo do enunciado, principalmente articulando a negação com as noções de ironia e a marca enunciativa da caixa alta. 
responsabilidades pelo enunciado] é utilizada não somente pra dar a conhecer o discurso atribuído a alguém mas também para [...] apresentar um discurso imaginário ("Se alguém me dissesse vou sair, eu lhe responderia...")" (parênteses explicativos nossos). Compreendemos, então, que funciona aí uma espécie de "Se alguém me dissesse que o PL 122 morreu, eu gritaria que ele não morreu, embora devesse ter morrido”.

Vejamos, a seguir, o funcionamento da ironia presente nesses enunciados.

\subsection{A ironia}

Percebemos que, no jogo de presença de enunciadores no enunciado por nós analisado, havia formulada uma explícita ironia. É sobre essa ironia que, tal como Ducrot (1987), nos colocamos para refletir sobre “a pertinência linguística da noção de enunciador" (p. 197). Compreendemos que "o discurso irônico consiste sempre em fazer dizer, por alguém diferente do locutor, coisas evidentemente absurdas, a fazer, pois, ouvir uma voz que não é a do locutor e que sustenta o insustentável” (Ibidem). Desse modo, tomamos o dizer entre aspas de Bolsonaro não como sendo atribuição do locutor, mas como um apontar o absurdo de um outro dizer, sustentado por um outro locutor, presente sob a forma de um enunciador.

Não se trata, no entanto, de um absurdo empiricamente existente no dizer de outrem, mas da formulação do dizer de outrem como absurdo - presente como um enunciador outro - no dizer do próprio locutor. Essa notação se torna mais apreensível justamente a partir da distinção ducrotiana de locutor e enunciador. Distinção que o autor faz intervir nas teses de Sperber \& Wilson (1978) para formular sua própria noção de ironia. Segundo Ducrot, "para que nasça a ironia, é necessário que toda marca de relato desapareça, é necessário 'fazer como se' este discurso fosse realmente sustentado, e sustentado na própria enunciação" (1987, p. 198). É desse modo que, para que funcione a ironia, o enunciado produzido por Bolsonaro "faz de conta" que gostaria que fossem criminalizadas "a carecofobia, flamengofobia, corithianofobia, magrelofobia $e$ peitocaídofobia". Trata-se de equiparar a homofobia - implicitamente presente pelo dispositivo enunciativo da interrogação, que norteia todo o enunciado - ao absurdo sustentado por um outro enunciador. O efeito que daí deriva é a equiparação do preconceito e violência sofrida por pessoas LGBT a uma suposta violência sofrida por carecas, flamenguistas, corinthianos, magrelos e pessoas de peito caído. 
Vejamos, no próximo tópico, a maneira como o operador argumentativo e o funcionamento do arrazoado são mobilizados dando certa direção ao sentido do enunciado em questão.

\subsection{O operador argumentativo "e digo mais" e o arrazoado por autoridade}

Após a enumeração que fica em suspenso no enunciado pela inserção das reticências, o funcionamento do operador argumentativo "e digo mais" chamou nossa atenção pela maneira como ele articula o que é dito antes dele com o que é dito depois, introduzindo um arrazoado por autoridade de modo muito específico. O arrazoado por autoridade é uma das formas pelas quais um argumento se apresenta no interior de um enunciado, tendo em vista a noção de polifonia. Ducrot (1987) demonstra que o arrazoado por autoridade pode ocorrer em duas etapas: na primeira, um locutor L mostra um enunciador $\mathrm{E}$ asseverando que um personagem $\mathrm{X}$ assevera algo, como em "o rapaz afirma estar curado". Na segunda, o enunciado mostra um enunciador assimilado ao locutor, em que este último é apresentado, pela sua situação ou pela sua competência, na condição de responder pelo enunciador. No enunciado em questão, é esta segunda forma de arrazoado por autoridade que está em presença.

Ao afirmar que "a maioria dos homossexuais é contra essa palhaçada que está aí no Senado", o locutor não só qualifica a criminalização da homofobia como "palhaçada" como faz uso da palavra em nome de "a maioria dos homossexuais". Ressaltamos, aqui, o poder criador da linguagem ao produzir um argumento de autoridade que sequer necessita de uma prova no mundo para ser tomado como verdade. $\mathrm{O}$ argumento é, pois, manipulado como a própria prova.

Para a discussão neste tópico proposta, valemo-nos da distinção feita por Ducrot (1987, p. 141) quanto aos sentidos possíveis para o verbo “dizer”, retomando as noções de mostrar e asseverar. Observe que, ao fazer tal afirmação, Bolsonaro (L1 - locutor 1) não mostra o que diz no interior mesmo do enunciado. De outro modo, L1 assevera algo que precisa ser remetido ao dizer de outro locutor (L2), que seriam os homossexuais. Dito de outra maneira, a enunciação remete a uma outra enunciação que lhe é anterior. Nesta enunciação anterior, que comparece na enunciação de Bolsonaro como L2, os homossexuais supostamente afirmam-se contra o projeto de criminalização da 
homofobia. Trata-se, aqui, nos termos de Ducrot (1984), de um arrazoado por autoridade, produzindo efeitos no dizer de Bolsonaro ${ }^{11}$.

É necessário salientar que o fato de o locutor não se apresentar identificado empaticamente com os homossexuais põe em questão a legitimidade de esse locutor falar em nome dos homossexuais. Voltaremos a esse ponto posteriormente, quando tratarmos das posições-sujeito no discurso.

Nesse ínterim, interessou-nos a força com que esses dois argumentos -1 . a qualificação da criminalização como "palhaçada" e 2. o uso do argumento de autoridade - ganham com o uso do operador "e digo mais". Ao mobilizar tal operador argumentativo, admite-se que não é só porque a criminalização da homofobia é mais uma banalidade entre outras (tal como descrevemos pelo funcionamento da ironia) que ela deve ser compreendida como absurda, mas, mais ainda, porque ela é uma palhaçada e porque os próprios homossexuais, em sua maioria, alegadamente são contra ela.

Em seguida, trataremos de algumas questões acerca do morfema "fobia" relativas a um dos processos de formação de palavras presente no enunciado por nós analisado.

\subsection{O morfema "-fobia"}

Observamos, pois, a maneira como a formação de determinadas palavras que aparecem no dizer de Bolsonaro argumentam em uma certa direção. Desse modo, analisamos, do ponto de vista argumentativo, a emergência das palavras "carecofobia, flamengofobia, corithianofobia, magrelofobia, peitocaídofobia". Trata-se de palavras que não constam no uso cotidiano, elas não foram reconhecidas oficialmente nem extraoficialmente, isto é, essas palavras não foram dicionarizadas ou adotadas formalmente, tampouco compõem o uso corrente, ainda que informalmente. Pusemo-nos às voltas com a noção de neologismo.

De acordo com Alves (1984), um neologismo precisa cumprir uma série de requisitos para que seja reconhecido como produtivo na língua. Esses requisitos consistem em critérios morfossintáticos, semânticos e fonológicos. Em uma abordagem teórica diferente da autora, tomaremos apenas aqui o fato expresso pela estrutura formativa dessas palavras que emergem. Estamos diante, pois, de padrões produtivos de formação de palavra por composição cujos segmentos são reconhecidos tanto morfofonologicamente - já que o aspecto morfossintático não nos interessa ao tomá-las

\footnotetext{
${ }^{11}$ Trataremos, mais à frente, da noção de falácia inerente ao processo discursivo que se desdobra aqui.
} 
isoladamente - quanto semanticamente. Assim, por justaposição, o mecanismo dispõe junto à palavra "fobia" uma série de outras palavras antes a ela não relacionadas, mas cujo encaixe é virtualmente possível pelos mecanismos produtivos da língua.

Ocorre, desse modo, no esquema de funcionamento e encaixe desses padrões produtivos, a aliança entre duas palavras cheias para designar um novo fato ou fenômeno (existente empiricamente ou imaginado). Assim, temos, por exemplo, a palavra homofobia, que designa o preconceito e a aversão à homossexualidade; e a transfobia, que designa o preconceito e a aversão a pessoas transgênero. Também são palavras formadas a partir desse padrão: xenofobia, aracnofobia, fotofobia, claustrofobia e muitas outras. Note-se, no entanto, que semanticamente é possível organizar essas palavras em campos semânticos distintos. Para nós, há aí a intervenção do uso político da noção de "fobia" em sua história recente, o que produz uma marcada distinção quanto ao seu sentido e sua mobilização no interior dos enunciados. Trata-se, no caso de homofobia e transfobia, por exemplo, de uma ressignificação do sentido de "fobia" deslocando-o simplesmente do sentido médico-patológico em que surge para um sentido em que também intervém em seu processo de constituição um sentido político - mais especificamente o de uma patologia social. Perceba-se, ainda, que no caso de homofobia, transfobia e xenofobia, a "fobia" se direciona a seres humanos que são apresentados no interior dos enunciados em sua suposta inferioridade. Um ponto de distinção pode ser o fato de que enquanto a "fobia" direcionada a animais e objetos significa aquele que fica acuado, a "fobia" direcionada a seres humanos significa aquele que fica agressivo e que comete - ou autoriza-se a cometer - violência. ${ }^{12}$

O que há em comum entre essas palavras é que elas designam objetos que provocam no outro uma certa aversão, que pode estar associada ao medo, ao não suportar, ao desconhecimento, à reação violenta, etc. Afirmamos isso - é importante ressaltar -, ainda que, como dissemos acima, possamos distinguir semanticamente a ordem dessas aversões. São aversões.

Como vimos, o enunciado no qual se formulam tais neologismos é irônico. A inserção argumentativa dessas palavras no enunciado, portanto, faz apontar para uma implicação: se existe aversão aos homossexuais - a homofobia - existe também aversão aos carecas, aos flamenguistas, aos corinthianos, aos magrelos e às pessoas de peito caído. Tal implicação, aliada à ironia na qual se insere, encaminha para a conclusão de que a

\footnotetext{
${ }^{12}$ Sobre este último ponto, agradeço ao olhar atento da professora Sheila Elias de Oliveira.
} 
violência sofrida pelos homossexuais é da mesma gravidade (ou, nesse caso, da não gravidade) daquilo porque sofrem essas outras pessoas, os LGBT. Isso, por sua vez, sustenta a conclusão maior de que a homofobia não deve ser criminalizada.

Feitas essas análises sobre a articulação estrutural desses enunciados, passemos a algumas considerações sobre a relação - para nós necessária - entre língua e exterioridade.

\section{Algumas considerações sobre a relação entre língua e exterioridade}

Oswald Ducrot, na segunda fase de sua Teoria da Argumentação na Língua, recorre ao conceito de topos, definido como "lugar comum argumentativo" (DUCROT, 1989, p. 13), para sustentar o fato de que um mesmo enunciado pode, por vezes, apontar para conclusões diferentes e que enunciados diferentes podem, igualmente, apontar para uma mesma conclusão.

Sem adentrar à vasta discussão empreendida pelo autor, nos contentamos em assinalá-la e acenar para um outro modo de observar a argumentação. Partindo da relação entre língua e exterioridade como constitutiva e ainda ancorando-se em uma abordagem estrutural, acompanhamos, a partir de agora, o gesto teórico de Guimarães (1995), propondo a relação com a Análise de Discurso, para analisar esses fatos de linguagem sob a tomada de posição materialista, conforme anunciamos nos pressupostos teóricos deste trabalho.

Tomamos a enunciação, portanto, como "a língua posta em funcionamento pelo interdiscurso no acontecimento" (GUIMARÃES, 1995, p. 86), considerando-se, ainda, "a enunciação como um acontecimento no qual se dá a relação do sujeito com a língua" (GUIMARÃES, 2017, p. 10). Nesse sentido, assumimos que a grande questão é o modo como descrevemos e analisamos esta relação do sujeito com a língua. O problema consiste, pois, em "como tratar a enunciação como funcionamento da língua sem remeter isto a um locutor, a uma centralidade do sujeito" (GUIMARÃES, 2017, p. 15). Ressaltar essa não remissão a uma centralidade do sujeito tem uma importância fulcral em nossa abordagem teórico-metodológica, conforme demonstramos a seguir.

As pesquisas em linguagem, principalmente nas abordagens em que o corpus é produzido por figuras públicas, como é o nosso caso, por vezes podem enfrentar uma pequena - mas às vezes pesada - incompreensão. Ao analisar um fato de linguagem produzido por alguém - todo fato de linguagem é produzido por alguém -, em uma abordagem linguístico-semântico-discursiva, o que interessa é o fato de linguagem. Não 
nos interessa a pessoa em si, empiricamente, tomada em sua individualidade ou unidade psicológica, jurídica, moral, etc.; de outro modo, interessa-nos compreender a produção desse fato de linguagem em um quadro mais abrangente, em que esse indivíduo não é mais indivíduo na medida que ele ocupa uma posição no processo de tomada da palavra. Ou seja, partimos do pressuposto de que "não se enuncia enquanto ser físico, nem meramente no mundo físico. Enuncia-se enquanto ser afetado pelo simbólico e num mundo vivido através do simbólico" (GUIMARÃES, 2017, p. 15). Portanto, não é nosso objetivo fazer qualquer análise jurídica, psicológica, moral ou o que quer que seja sobre Bolsonaro enquanto indivíduo; é, sim, nossa finalidade, tomá-lo a partir de sua posição que, inclusive poderia ser ocupada por outrem -, inserindo a produção dos dizeres a ele atribuídos nesse quadro mais abrangente que é o de uma posição materialista na análise da argumentação pela articulação entre teoria da enunciação e análise de discurso.

Nessa linha teórica, compreendemos que "enunciar é uma prática política em um sentido muito preciso" (GUIMARÃES, 2017, p. 11). Qual seja? No sentido de político que advém das posições epistemológicas materialistas. Assim, temos "o político como algo que é próprio da divisão que afeta materialmente a linguagem e (...) o acontecimento da enunciação" (GUIMARÃES, 2017, p. 20). Propomo-nos, pois, a "tratar o político como fundamento das relações sociais, no que tem importância central a linguagem" (GUIMARÃES, 2017, p. 21).

Ao trazer ao fundamento da questão a noção de político, em que se marca o fato da divisão, faz-se, também, presente o fato do funcionamento da língua em sua historicidade na relação com a memória discursiva. A noção de historicidade deriva da relação com a Análise de Discurso. De acordo com Orlandi (2013), a história é constituída na/pela ideologia (enquanto força material), sempre na tensão do funcionamento do político - este último compreendido como divisão de sentidos. Na esteira desse modo de tratamento teórico, para Guimarães (2017), é necessário compreender o político como instaurador de uma divisão no real, instalando na linguagem a contradição que deriva do estabelecimento de uma normatividade. Sendo assim, partiremos aqui do pressuposto de que a historicidade é sempre-já em relação ao político definido como "o fato de que o sentido está sempre dividido, tendo uma direção que se especifica na história, pelo mecanismo ideológico de sua constituição" (ORLANDI, 1996, p. 22).

Nesse quadro, um conceito importante para esta análise, mobilizado por Guimarães (1995) em sua concepção de enunciação, é o de interdiscurso. De acordo com Orlandi (2013, p. 31), o interdiscurso "é definido como aquilo que fala antes, em outro 
lugar, independentemente [...] o saber discursivo que torna possível todo dizer e que retorna sob a forma do pré-construído, o já-dito que está na base do dizível, sustentando cada tomada de palavra".

É por meio dessa noção de memória - constituída pelo funcionamento da ideologia e em relação com as condições de produção do discurso -, que sustenta a tomada da palavra, que retomamos alguns pontos de análise estrutural que fizemos anteriormente.

Lembremos aqui o que dissemos, do ponto de vista da semântica estruturalista, sobre os argumentos que constam nos enunciados analisados encaminharem-se (nos) para a conclusão de que a homofobia não deve ser criminalizada, já que ela é tão banal quanto o preconceito sofrido por um careca ou um flamenguista.

Bolsonaro, ao conceder tal entrevista e, posteriormente, ao reescrever os enunciados em sua rede social, ocupa, no discurso, uma posição-sujeito ${ }^{13}$ muito específica. Inscreve-se, discursivamente, na polêmica em torno da criminalização da homofobia e no jogo de tensões que começa a se delinear para as eleições de 2014. Tratase da posição-sujeito político de direita em ascensão.

É no encadeamento argumentativo - tal como o descrevemos -, no entanto, que os sentidos ganham sua espessura material.

Para a Análise de Discurso, o discurso é "efeito de sentidos entre interlocutores" (Pêcheux, 1969 [2014]). Pelo mecanismo de antecipação (Pêcheux, 1995 [1975]) que regula a noção de formações imaginárias, é possível que tais efeitos de sentido signifiquem aquele que toma a palavra.

É nessa direção que retomo o funcionamento da rede social para comentar a impressão de que funciona, discursivamente, uma sobreposição entre locutor e sujeito falante. Principalmente levando-se em consideração a tensão da disputa política, há um efeito de unicidade do sujeito falante em funcionamento, produzindo o apagamento do agenciamento do locutor e dos enunciadores no interior do enunciado.

O funcionamento da ironia, a mobilização feita pela negação, o encadeamento pelos operadores argumentativos e a produção de neologismos naturalizam-se; e, ao passo que esse processo se dá, engendra-se um efeito de verdade sobre o dizer. É como se o sujeito não estivesse argumentando, mas colocando verdades, absolutas, inclusive com

\footnotetext{
${ }^{13} \mathrm{O}$ conceito está aqui situado conforme propõe Michel Pêcheux (2014, [1969]). Trata-se do fato de que o indivíduo, ao ser interpelado ideologicamente em sujeito ocupa uma posição historicamente determinada dentro de uma formação discursiva. Essa posição constitui o seu dizer.
} 
um argumento de autoridade: que a maioria dos homossexuais concordam que a criminalização da homofobia é uma palhaçada e são contrários a ela. Ao retomar a questão da argumentação por autoridade na forma de um arrazoado por autoridade, acenamos para o caráter falacioso dessa construção no que se refere ao regime de asseveração. Não há evidências em forma de fatos de linguagem que possibilitem a afirmação de que a maioria dos homossexuais é contrário à criminalização da homofobia.

De outro modo, mas também nessa direção, o locutor constituído pelo dizer de Bolsonaro não é legitimado no lugar social de dizer em nome dos homossexuais, que historicamente constituem, pelos movimentos sociais, uma determinada forma de representação e um direcionamento de pautas. O que constitui a autoridade evocada no enunciado é, portanto, falso. Ressaltamos, pois, que é falso o que constitui a autoridade não porque os homossexuais não tenham condições de falar sobre o PL, mas porque o locutor não está em condições sócio-históricas de evocá-los e porque "a maioria" não é atestada tal como ele a apresenta; e tampouco esse locutor é apresentado no enunciado empaticamente identificado àqueles a quem se refere.

Em uma perspectiva materialista, compreendemos que a argumentação na língua - tal como a própria língua - é determinada historicamente, pelo funcionamento da ideologia que recorta o interdiscurso, o todo possível do dizer.

Assim, considerando Bolsonaro a partir da posição-sujeito político de direita em ascensão - nas condições de produção em que se encontrava o Brasil da época (tanto no que se referem aos embates políticos quanto aos modos de atribuir sentido às questões de sexualidade) -, entendemos que é a existência do interdiscurso e sua relação com a ordem da língua que possibilita a pertinência de tal encadeamento, presentificando determinadas memórias sobre a criminalização da homofobia, significando-a no lugar de uma pauta desnecessária - fato que ela se equipara à corinthianofobia e a peitocaídofobia - ou até mesmo perigosa - já que "O PL NÃO MORREU”, continua vivo, mas deveria estar morto.

Pelo funcionamento da ideologia na relação com o interdiscurso, a memória funciona de um modo específico e intervém no processo de significação dos enunciados ditos por Bolsonaro. A maneira como, historicamente, a homossexualidade é compreendida em nossa formação social retorna sobre esses enunciados, fazendo presentes as tensões e divisões constituídas pelas relações de força entre o que se estabeleceu como o normal/certo e o que se estabeleceu como o anormal/errado. 


\section{Conclusão}

Neste trabalho, valemo-nos da semântica argumentativa, em um primeiro momento, para depois tecer algumas considerações a partir da posição materialista, fazendo intervir a noção de política e a relação entre língua e exterioridade.

Retomando brevemente alguns pontos que nos parecem carentes de atenção, ressaltamos que, ao conhecer a posição de Guimarães (1995), fomos levados a reconhecer os limites de considerar a negação do enunciado que analisamos como sendo uma negação descritiva, tal como havíamos pensado em considerar enquanto analisamos o enunciado em perspectiva estritamente estrutural. Ao tomar o funcionamento do político e fazer intervir a noção de interdiscurso, por meio da qual compreendemos que algo fala sempre antes e independentemente, compreendemos que essa negação não é meramente descritiva, mas está em relação a um dizer anterior situado na memória, ainda que não atestado explicitamente na língua.

No mais, ao elencarmos como questão primeira a produção do sentido, esperamos ter sido bem-sucedidos ao demonstrar, a partir dos autores e aparatos teóricos articulados, 1. os mecanismos linguísticos de encaixe pelos quais se apresentou a argumentação dos enunciados por nós analisados; e 2. que esses mecanismos que se apresentaram nos enunciados que analisamos são afetados pelo interdiscurso, o que produz efeitos na maneira como os enunciados serão lidos e interpretados.

A compreensão dos mecanismos pelos quais se constituem o sentido desses enunciados é fundamental para discutirmos, por exemplo, a importância da contribuição da semântica para pensar a política. Afinal, vimos que os enunciados apresentam um locutor irônico, incomodado e desdenhoso da criminalização da homofobia, ainda que haja dados, números e fatos que atestem a sua importância.

Ao mobilizar a noção de político, fundamentalmente há de se considerar as tensões, relações de força e de poder que se presentificam no dizer, principalmente no dizer da política, que é polêmico no sentido de que explicita a divisão de posições, a partir das disputas já expressas linguisticamente e atestadas pelo fato da argumentação, conforme já propusera Oswald Ducrot. O que vemos é a mobilização dos mecanismos linguísticos em uma argumentação que se dá em prol de uma perspectiva redutora e desagregadora sobre o direito do outro, sendo esse outro - os homossexuais - cinicamente evocados nesse processo de argumentação.

Se enunciar é se inscrever por meio da língua em uma posição em um processo dividido por relações desiguais, podemos considerar que um deputado que se coloca 
contra um projeto de criminalização da homofobia associa-se ele mesmo à homofobia.

Afinal, como vimos, dizer quase nunca é uma simples constatação. Nesse caso, é tomada de posição em prol de um projeto que visa à acentuação das desigualdades já postas em uma formação social complexa e contraditória.

\section{Referências bibliográficas}

ALVES, I. M. A integração nos neologismos por empréstimo ao léxico português. Alfa: São Paulo/SP, n. 28, p. 119 - 126, 1984.

DUCROT, O. \& ANSCOMBRE, A. L'argumentation dans la langue. Langages, 10e année, n42, 1976. pp. 5-27.

DUCROT, O. Argumentação retórica e argumentação linguística. Letras de Hoje, Porto Alegre, v. 44, n. 1, p. 20-25, jan./mar. 2009.

DUCROT, O. Dire et ne pas dire. Hermman, Paris, 1972.

DUCROT, O. (1984) O dizer e o dito. Trad. Eduardo Guimarães. Campinas/SP: Pontes, 1987.

DUCROT, O. Argumentação e "topoi” argumentativos. In: Eduardo Guimarães (org). História e sentido na linguagem. Campinas/SP: Pontes, 1989.

DUCROT, O. Topoi e as formas tópicas. 1988. In: Ana Zandwais (org). Relações entre pragmática e enunciação. Porto Alegre/RS: Editora Sagra Luzzato, 2002.

ELIAS DE OLIVEIRA, S. Igreja Universal do Reino de Deus: Uma análise de argumentação em perspectiva discursiva. (1998). 117 f. Dissertação - IEL/Unicamp, Campinas/SP, 1998.

ELIAS DE OLIVEIRA, S. Sobre o funcionamento do político na linguagem. Revista Línguas e Instrumentos Linguísticos, n 34, jan-jun. 2014.

GONÇALVES, C. A. V. Atuais tendências em formação de palavras no português brasileiro. SIGNUM: Estud. Ling., Londrina, n. 15/1, p. 169-199, jun. 2012.

GUIMARÃES, E. Os limites do sentido: um estudo histórico e enunciativo da linguagem. Campinas/SP: Pontes, 1995.

GUIMARÃES, E. Semântica do acontecimento: um estudo enunciativo da designação. 4 ed. Pontes: Campinas/SP, 2017.

ORLANDI, E. A linguagem e seu funcionamento. 2 ed. Campinas/SP: Pontes, 1987.

ORLANDI, E. Análise de discurso: princípios e procedimentos. 6 ed. Campinas/SP: Pontes, 2013.

ORLANDI, E. Discurso e argumentação: um observatório do político. Revista Fórum Linguístico. Florianópolis, n. 1 (73-81), jul.-dez. 1998.

ORLANDI, E. Interpretação: autoria, leitura e efeitos do trabalho simbólico. 2 ed. Petrópolis/RJ: Editora Vozes, 1996.

PÊCHEUX, M. Análise Automática do Discurso. 1969. In: Françoise Gadet \& Tony Hak. Por uma análise automática do discurso: introdução à obra de Michel Pêcheux. Campinas/SP: Editora da Unicamp, 2014. 
PÊCHEUX, M. Semântica e Discurso: uma crítica à afirmação do óbvio. Campinas/SP: Editora da Unicamp, 1995.

RANCIÈRE, J. (1992). Os nomes na história. São Paulo: Educ/Pontes, 1994.

ZOPPI-FONTANA, M. G. Argu(meme)ntando: argumentação, discurso digital e modos de dizer. In: Eduardo Lopes Piris \& Isabel Cristina Michelan de Azevedo (org). Discurso e argumentação: fotografias interdisciplinares. Volume 1. Coimbra: Grácio Editor, 2018.

ZOPPI-FONTANA, M. G. Cidadãos modernos: discurso e representação política. 2 ed. Campinas/SP: Editora da Unicamp, 2014.

Data de Recebimento: 30/08/2021

Data de Aprovação: 17/11/2021 


\section{Para citar essa obra:}

FATIMA, Wellton da Silva de,. Uma análise argumentativa do sentido de "homofobia" na enunciação de Jair Bolsonaro (2014). In: RUA [online]. Volume 27, número 2 - p. 411-433- e-ISSN 2179-9911 - novembro/2021. Consultada no Portal Labeurb Revista do Laboratório de Estudos Urbanos do Núcleo de Desenvolvimento da Criatividade.

http://www.labeurb.unicamp.br/rua/

Capa: Figura 1: print screen da postagem feita por Jair Bolsonaro em sua página oficial no Facebook. Fonte: o autor.

Laboratório de Estudos Urbanos - LABEURB

Núcleo de Desenvolvimento da Criatividade - NUDECRI

Universidade Estadual de Campinas - UNICAMP

http://www.labeurb.unicamp.br/

Endereço:

LABEURB - LABORATÓRIO DE ESTUDOS URBANOS

UNICAMP/COCEN / NUDECRI

CAIXA POSTAL 6166

Campinas/SP - Brasil

CEP 13083-892

Fone/ Fax: (19) 3521-7900

Contato: http://www.labeurb.unicamp.br/contato 